\title{
É POSSÍVEL SE FALAR EM POLÍTICA NO CONSUMO COMO RECURSO NA PROMOÇÃO DE MARCAS JUVENIS? CONSIDERAÇÕES A PARTIR DA CAMPANHA: OI, BLOQUEIO NÃO!
}

\section{Is it possible to talk about the politics in consumption as the promotion of youth brands? Consideration about the campaign: OI, BLOQUEIO NÃO.}

\author{
Mônica Machado ${ }^{1}$
}

\begin{abstract}
Resumo
O artigo discute o conceito de politização do consumo como recurso de construção de marcas juvenis. Recorre a pressupostos teóricos para refletir sobre os vínculos entre juventude, consumo e política. Estuda a campanha Oi, Bloqueio Não! como linha de comunicação que busca engajamento juvenil em um movimento que se pretende em defesa da cidadania. Objetiva-se, então, o questionamento desta premissa, discutindo as potencialidades e limitações discursivas da marca Oi em sua proposição política.
\end{abstract}

Palavras-chave: política e consumo, politização de marcas, campanha “Oi, Bloqueio não!"

\begin{abstract}
This paper analyzes the concept of consumer politicization and use of building youth brands. It uses theoretical frame to reflect on the links between youth, consumption and politics. It studies the campaign “Oi, Bloqueio Não!”, it's a line of communication that seeks youth involvement in a movement that aims to promote citizenship. The point is, then, to question this premise, that discusses the potential and limitations of discursive Oi brand in its policy proposition.
\end{abstract}

Key-words: policy and consume, politicization of trade marks, campaign "Oi, Bloqueio Não!"

\section{Resumen}

El artículo analiza el concepto de politización de consumo y uso de la construcción de marcas jóvenes. Uso de supuestos teóricos para la reflexion sobre los vínculos entre los jóvenes, el consumo y la política. El estudio de la campaña “Oi, bloqueio Não!” como línea de comunicación de una marca que busca la participación de los jóvenes en un movimiento que intenciona promover la ciudadanía. El objetivo es, entonces, la cuestión esta premisa,

${ }^{1}$ Professora Assistente da Escola de Comunicação ECO/UFRJ Doutoranda do Programa de Pós-Graduação da ECO-UFRJ 
É possível se falar em política no consumo como recurso na promoção de marcas juvenis? Considerações a partir da campanha: oi, bloqueio não!

discutiendo el potencial y las limitaciones de la propuesta discursiva de la marca Oi en su concepto político.

Palabras-clave: política y consumo, la politización de las marcas, campaña "Oi, Bloqueio Não!"

\title{
1. INTRODUÇÃO
}

Há inúmeras vocalizações na contemporaneidade sobre o papel do consumo na formação das identidades juvenis relacionadas à cidadania. $\mathrm{O}$ direito à diversão, ao lazer, à participação mais ativa na economia de mercado está na agenda das políticas públicas dirigidas à juventude em diversos países e também nas pautas dos próprios atores jovens em suas reivindicações por mais oportunidades de participação nas sociedades de consumo ${ }^{2}$.

Simultâneo a esse fenômeno observa-se o declínio da participação juvenil nos modos clássicos de representação da política. Nota-se o distanciamento das culturas juvenis das arenas tradicionais de representação do sistema democrático: os partidos políticos, a militância política, a participação em movimentos de associativismo: sindicatos, associação de moradores ou mesmo grêmios estudantis. ${ }^{3}$

Ao pensar na concepção da sociedade contemporânea, Canclini aposta no papel do consumo na construção das novas identidades, em especial quando se refere à juventude:

\begin{abstract}
Vivemos num tempo de fraturas e heterogeneidade, de segmentações dentro de cada nação e de comunidades fluídas com as ordens transnacionais de informação, da moda e do saber. Em meio à heterogeneidade encontramos códigos que nos unificam, ou ao menos permitam que nos entendamos. Mas estes códigos compartilhados são cada vez menos os da etnia, da classe ou da nação em que nascemos. Essas velhas unidades de medida que subsistem, para se reformular como pactos móveis de leitura dos bens e das mensagens. (CANCLINI, 1995: 62)
\end{abstract}

Nesta perspectiva, o consumo assumiria função mediadora na construção de um novo sentido de sociedade. $\mathrm{O}$ autor discute as possibilidades de um contemporâneo senso de cidadania mais associado ao consumo privado de bens e a mídia, dos que "as regras abstratas da democracia ou na participação coletiva em espaços públicos.” (1995:13).

\footnotetext{
${ }^{2}$ Cf. RIBEIRO, Eliana; NOVAES, Regina. Jovens da América do Sul: situações, demandas e sonhos mobilizados. In: Democracia Viva. Março 2008, no. 38.

${ }^{3}$ Cf. Relatório Instituto Cidadania 2004. O estudo quantitativo revela que $85 \%$ dos jovens no Brasil dizem espontaneamente que não participam de nenhuma atividade de associativismo. Dos $15 \%$ que participam, $4 \%$ estão engajados em movimentos religiosos; $3 \%$ em grupos musicais; $2 \%$ em atividades de dança; iguais $2 \%$ em teatro; $1 \%$ em grupos de futebol. E ainda outros 3\% disseram respostas muito pulverizadas. Quando os pesquisadores estimulam as respostas, temos os seguintes resultados: $17 \%$ participam de grupos religiosos; $3 \%$ de clubes/ associações desportivas; $2 \%$ de grêmios estudantis; $2 \%$ de associações de moradores; $2 \%$ a grupos ligados ao movimento anti-racismo e $1 \%$ de partidos políticos.
} 
É possível se falar em política no consumo como recurso na promoção de marcas juvenis? Considerações a partir da campanha: oi, bloqueio não!

Em contrapartida, Habermas argumenta que o novo cenário da modernidade tardia traz indícios de esvaziamento da esfera pública convencional e retração para o universo do privado. E nos propõe pensar sobre o processo de despolitização da sociedade contemporânea. Argumenta que há, no cenário atual, a encenação de uma esfera pública política e que sua representação se dará publicitariamente. Para o autor, o "consumidor político contemporâneo" é o "novo indiferente", destituído de sua vocação na esfera pública burguesa: a da participação e do pertencimento (1984: 253).

Bauman, na mesma linha, ao refletir sobre a referência do exercício político no mundo contemporâneo, sinaliza a "apatia política". Argumenta que as instituições políticas estão esvaziadas de poder na sociedade de consumo, que vivemos na era "pósideológica"; "pós-utópica" e acredita que trocamos "a preocupação com o bem estar público pela liberdade de buscar a satisfação pessoal” (2008: 28).

Frente a essas posições antagônicas, interessa-nos perguntar então, o que os discursos no campo de consumo têm a dizer sobre os novos pertencimentos políticos e novos sentidos de cidadania relacionados aos jovens? Em que medida é possível pensar a circulação dos discursos publicitários dirigidos aos jovens com conotações de cidadania e participação política?

Objetivo, em linhas gerais, defender a hipótese de que, frente à fragilidade das instituições da democracia representativa em criar conexões com as culturas juvenis, as corporações mundiais têm se esforçado para capturar a energia política das juventudes, hoje pulverizada, ao trabalhar a construção de suas marcas publicitariamente conotando engajamento, participação e estímulo à cidadania.

Partimos da defesa de que é necessário questionar as potencialidades e limitações da linguagem publicitária quando lida como operador mágico-totêmico ${ }^{4}$ no mundo contemporâneo e mediadora de relações sócio-culturais e refletir sobre o quanto promove o "sentido de pertencimento e identidade em comunidades transnacionais de consumidores" (CANCLINI, 1997: 28). A proposição inicial de nosso argumento é de que a promoção da cidadania e do engajamento político nos discursos da publicidade de bens tem limitações. Os ideais de liberdade, autonomia, independência inscritos nos textos que prometem eficácia simbólica de produtos tangíveis parecem aprisionados ao mundo das marcas e tornam-se efêmeros no momento em que o circuito da compra se efetiva. Pode-se falar de

\footnotetext{
${ }^{4} \mathrm{O}$ conceito está posto no livro "Magia e Capitalismo" de Everardo Rocha. O autor discute o papel mediador da publicidade na tradução dos espíritos culturais das sociedades contemporâneas.
} 
É possível se falar em política no consumo como recurso na promoção de marcas juvenis? Considerações a partir da campanha: oi, bloqueio não!

um movimento de baixa politização da juventude contemporânea. Tomando por base, sua relação com os mecanismos de representação democráticos (onde incluiríamos o baixo interesse pela propaganda política-eleitoral), é possível pensar em outra politização associada ao consumo da publicidade dos bens. Se, em certa medida, as vocalizações das marcas das corporações estabelecem fortes conexões com as culturas juvenis criando mediações e códigos interculturais unificadores, estes vínculos parecem fluídos, fragmentados e mais individualizados do que coletivos.

As diretrizes conceituais para o projeto estão situadas nos estudos culturais que oferecem pistas para análise do papel mediador da mídia na construção de novas identidades, os movimentos de resistência, as novas representações, ideologias e valores. Cabe ressaltar, também, os pressupostos teóricos da análise do discurso, contribuindo no desvendamento dos modos de enunciação da linguagem da propaganda. Particularmente, oferecendo subsídios para o estudo do modo como os discursos publicitários conotando sentidos políticos são construídos e quais são os contextos de sua produção. Neste sentido, o projeto seguirá as orientações para a descoberta das marcas sociais no processo produtivo das mensagens: análise do contexto situacional imediato; do contexto institucional e do contexto sociocultural mais amplo (FOUCAULT, 1971; PINTO, 1993).

\section{MARCOS TEÓRICOS SOBRE A RELAÇÃO ENTRE JUVENTUDE, CONSUMO E POLÍTICA}

As linguagens da propaganda e da publicidade são recorrentemente reconhecidas como indícios expoentes da consolidação da cultura de mercado. E é por isso que durante o século XX suas formas mais variadas de representação estão no centro dos debates críticos sobre o advento da indústria cultural (ADORNO \& HORKHEIMER, 1947); da sociedade do espetáculo (DEBORD, 1967); ou na sociedade de consumo (BAUDRILLARD, 1968). Autores, portanto, de diferentes matizes teóricos e perspectivas históricas, mas que desenvolvem argumento comum: a crença na crítica à modernidade, a visão da propaganda e/ou a publicidade como instituições mais exponenciais do chamado pós-fordismo (SLATER, 2003), reforçam a idéia de desmaterialização da cultura, do desmanche das tradicionais estruturas de hierarquia social para adoção de "estilos de vida"; evocam a centralidade das relações, na vida privada e no mundo público, mediadas pelo mercado.

Só é possível pensar a emergência da cultura publicitária em um momento avançado da cultura de consumo na virada do século XIX para o século XX. Algumas pré-condições 
É possível se falar em política no consumo como recurso na promoção de marcas juvenis? Considerações a partir da campanha: oi, bloqueio não!

são necessárias para suas expressões: a progressiva concentração na produção de bens de consumo em substituição à produção de bens de capitais; o desenvolvimento de um sistema de comercialização de bens, inicialmente com foco na infra-estrutura do varejo com a criação das lojas de departamento e galerias; a projeção do ideal de modernidade associado ao consumo; o fortalecimento da cultura da mídia (MC KENDRICK, 1982; SLATER; 2003; KELLNER, 2003).

Entretanto, suas raízes estão fortemente associadas ao período em que as relações culturais e sócio-políticas passaram a ser progressivamente mediadas pelo mercado. A íntima relação entre o surgimento da cultura de consumo e ideal de modernidade contribui para a compreensão do quanto as representações do mundo contemporâneo sobre o sujeito, seus ideais de liberdade cívicos e as relações sociais passam pela mediação do consumo. E, exato por isso, a tradição crítica a esse modo dominante de reprodução cultural tem uma história de expressão.

O projeto de modernidade tem forte vínculo com o percurso da cultura de consumo. Um modo de expressão cultural identificado com o Ocidente Moderno onde: a ideologia vigente fala que o sujeito é livre e racional como indivíduo e "o mundo é governado pela abundância, organização racional, o saber científico, a figura do consumidor e a experiência do consumismo" (SLATER, 2002:30).

Inspiradas na tradição do liberalismo, as mediações do consumo tendem a dar os referenciais para o modelo do sujeito moderno. Veremos como a criação discursiva do conceito de juventude enquanto categoria social ganha substancialmente traços da idealização deste sujeito moderno: que enaltece a liberdade de escolha racional, centrada no individualismo, ambientado na cultura da abundância e recolhendo indícios das mediações do consumo para as construções de identidade.

Empreendemos o esforço de entender como os discursos sobre as culturas juvenis passam a povoar o imaginário social no período histórico que coincide com o marco da consolidação da cultura de consumo. Naturalmente, ao pensar as condições de vida dos segmentos jovens inúmeros discursos convergem para a centralidade das práticas de consumo no debate sobre identidades juvenis.

Desde o fim do século XIX, observa-se o crescente interesse por discursos sobre a emergência da juventude enquanto categoria social (HALL, 1994; GRIFFIN, 1993). São reflexões que alternam o debate de liberdade e controle das culturas juvenis e que matizam mudanças fisiológicas, emocionais, culturais ou sociopolíticas nesta faixa etária. No século 
É possível se falar em política no consumo como recurso na promoção de marcas juvenis? Considerações a partir da campanha: oi, bloqueio não!

de Mônica Machado

XX inauguram-se os discursos sobre a cultura de consumo associada à juventude. As narrativas prevalecentes ainda oscilam entre as duas perspectivas: há as reflexões que associam o consumo a comportamentos patológicos, aos desvios de conduta e destacam os danos que a ideologia de consumo provoca na mente instável do adolescente (ABELSON, 1992; GRIFFIN, 1997; TIERSTEN, 2001; BURKE, 2006).

Mas surgem também, em contrapartida, narrativas que visualizam o consumo como espaço de mediações socioculturais capazes de auxiliar o indivíduo na marcação de sua individualidade, teses que vão associar as práticas de consumo aos movimentos de construção de vínculos identitários, especialmente quando dirigidos ao universo jovem. Nesta lógica, através dos usos sociais dos bens de consumo, a juventude negocia suas relações com o "lifestyle", marcando suas posições de singularidade no mundo. Segundo Canclini, dessa forma o consumo se revela como "um lugar de valor cognitivo, útil para pensar e atuar significativa e renovadoramente, na vida social" (1999: 92). Tendência que abre caminho para se discutir os modos de circulação de discursos de consumo dirigidos aos jovens.

O primeiro olhar dos estudos culturais para as questões juvenis tinham perspectivas mais ortodoxas: inserção profissional de jovens operários no mercado de trabalho, escolarização e as consequentes alterações de seus usos do saber e suas relações com os equipamentos culturais

E é neste contexto que as primeiras formulações sobre identidade jovem associada às práticas de consumo se efetivam. Como diz Matellart:

O retorno às formas de sociabilidade operária leva também a prestar atenção a uma dimensão que permanecera secundária em Hoggart: a das relações entre as gerações, das formas de identidades e subculturas específicas que mobilizavam os jovens dos meios populares. Múltiplos fatores trazem essa questão para a ordem do dia. (2004: 62).

Na década de 80, há um reaquecimento do mercado jovem americano: um fenômeno televisivo baseado em plataforma musical consolida o mercado jovem de mídia nos EUA: a MTV. Na busca de retomar o crescimento do mercado jovem, no fim dos anos 80 e início dos 90, as juventudes continuam a ser lucrativas e a influenciar as estratégias de marketing

\footnotetext{
${ }^{5} \mathrm{O}$ conceito de lifestyle é, na visão de Milles, o natural substituto do conceito de subculturas jovens. Para o autor, a noção de subculturas considerava pertencimentos de classe ou grupos socioculturais com interesses, gostos e visões de mundo relativamente homogêneas. Na contemporaneidade, os códigos culturais são amplamente pulverizados, fragmentados, por vezes provisórios, se interpenetram e por isso, de acordo com Milles, o conceito de subcultura envelheceu. Na sua perspectiva, falar em lifestyle (estilo de vida) é mais próximo desta multiplicidade de pertencimentos que, em especial, a juventude tem a seu dispor.
} 
É possível se falar em política no consumo como recurso na promoção de marcas juvenis? Considerações a partir da campanha: oi, bloqueio não!

na Inglaterra e nos EUA. É entre 70 e 80, que o crescimento do fenômeno se amplia para outros países do capitalismo ocidental.

Neste período, as discussões no campo dos estudos culturais avançam para os desdobramentos da cultura jovem e seus modos de inserção na vida social, econômica e política a partir de suas representações no mundo da cultura. O conceito de subcultura jovem é adotado por inúmeros pesquisadores dedicados aos estudos dos conflitos geracionais (HALL, 1993; HEBDIGE, 1979). O olhar para os códigos culturais dos jovens é absorvido para a reflexão sobre o lugar que ocupam na sociedade: o quanto de seus comportamentos e atitudes revela indícios de suas identidades; quais são os movimentos de resistência, de desvio, no sentido, de marcação da diferença e quais as atitudes que podem ser vistas como reafirmação da ordem instituída pela indústria da cultura e da sociedade de consumo.

O conceito de subculturas juvenis ganha relevância no diálogo com Maffesoli (1944) e a noção de "tempo das tribos". No prefácio à terceira edição francesa, o autor argumenta que a metáfora de tribos foi adotada para falar das "metamorfoses dos vínculos sociais" (1944 [2000]). Discute a idéia de que o neotribalismo pós-moderno fala dos vínculos comunitários, dos códigos de unificação que transcendem os vínculos clássicos de categorias sociológicas clássicas como classe, espaço geográfico; gênero. As bases para os laços de socialidade estão, no discurso de Maffesoli, tanto nos movimentos de vanguardas culturais da mídia, músicas, novas tecnologias quanto nas referências clássicas de construção de identidade.

A experiência de uso da expressão "novas tribos juvenis" especialmente na agenda jornalística é marcante até os dias de hoje. Mas, como observa o próprio Mafessoli, o conceito foi tratado superficialmente na cena midiática. Tribo virou sinônimo de estereótipo, ou seja, de um conjunto de referenciais que sugerem, a priori, a inserção de grupos juvenis com vínculos de dimensões plurais, mas que em geral unificam interesses do mundo do consumo: música, moda, cultura midiática. E, por vezes, visões de mundo em relação às causas sociais, ambientais, sexuais. Veremos, mais à frente como na cena da modernidade tardia a tendência é de esfacelamento destes vínculos de pertencimentos e do movimento de deslocamento do conceito de subculturas para o de lifestyle.

Nos anos 80, nota-se também o período da efervescência da crítica feminista que toma a questão de gênero e consumo como uma problemática dos estudos culturais (GRIFFIN, 1997; Mc ROBBIE, 1998). Nota-se também o reforço das teses questionando o 
É possível se falar em política no consumo como recurso na promoção de marcas juvenis? Considerações a partir da campanha: oi, bloqueio não!

grau de autonomia de adolescentes para formação de senso crítico na medida em que as instituições que historicamente respaldavam as bases para formação de identidade se fragilizam. McRobbie (1998), por exemplo, ao se referir às culturas juvenis femininas argumenta que o conceito de adolescente vinha formado em uma tradição de inter-relação entre os discursos familiares, educacionais, jurídicos e hoje está fortemente atrelada à cultura da mídia e de consumo. A menina adolescente se reconhece e está autorizada a se ver como tal a partir das imagens produzidas pelo universo do consumo. McRobbie (1998) propõe reativar as condições para a crítica feminista sobre a sociedade de consumo para criar outros regimes discursivos com visibilidade para se contraporem ao discurso hegemônico da sociedade de consumo.

No período denominado pós fordismo (SLATER, 2002; OSBERGY, 2004), os sistemas de produção são orientados a ofertar conteúdos altamente heterogêneos e customizados. Nesse sentido, a tendência dominante passa ser a de substituição do conceito de subculturas (categorias definidas por inserções socioculturais macros, como identificações por classe, gênero, posições políticas e religiosas) pelo conceito de lifestyle (que imaginariamente constrói a perspectiva de identidade mais fluída; associada a inúmeros fragmentos de vinculações como: preferências culturais por músicas; estilos de moda; gostos associados às tradicionais referências de gênero; classe etc.). Osbergy (2004) argumenta que especialmente as culturas juvenis vivem experiências culturais cada vez mais não-presenciais mediadas pela tecnologia e por isso têm identidades que recolhem indícios de fontes mais diversas. Hall (2002) ao refletir sobre as identidades culturais na pósmodernidade também defende posição similar: os sentimentos de pertencimento estão associados a inúmeras conexões que os sujeitos sociais fazem ao longo da vida. A transitoriedade da identidade estaria fortemente influenciada pela desterritorialização da cultura. Como diz Naomi Klein, tentando compreender as referências de identidades juvenis:

Essa garotada, como repetidamente ouvimos, vive não em um lugar geográfico, mas em um circuito de consumo global: conectam-se por seus celulares e newgroups da internet; unemse em torno de Sony Playstations; vídeos da MTV e jogos da NBA. (2004: p. 145)

No Brasil, a consolidação de um mercado juvenil de cultural nos ajuda na compreensão do advento do conceito de lifesyle. A emissora MTV, na versão Brasil, só é inaugurada nessa época. É também nesse período que surge um movimento na teledramaturgia brasileira que iria se firmar como referência para a cultura jovem: 
É possível se falar em política no consumo como recurso na promoção de marcas juvenis? Considerações a partir da campanha: oi, bloqueio não!

Malhação. A partir daí se proliferam os programas de TV aberta e por assinatura destinados à cultura jovem em suas mais variadas expressões. O mesmo ocorre no mercado de produção editorial: nota-se uma profusão de revistas femininas para adolescentes e várias outras publicações destinadas a jovens de diferentes estilos: apreciadores de videogames, música pop, heavy metal, moda etc. Quando as diferenciações e a fragmentação de identidades e interesses entre as juventudes se tornam ainda mais acentuadas que entre os adultos, a publicidade dialoga cada vez mais pontualmente com jovens de perfis distintos. Cresce o número de rádios e programas televisivos para esse público em diversas emissoras. Com o surgimento e popularização da internet, vê-se uma explosão de oportunidades para o crescimento do consumo cultural no mundo jovem: blogs, fotologs, Orkut, diversos sites de relacionamentos na web, MSN, Skype e outras ferramentas. São fenômenos que auxiliam a indústria da cultura a mapear perfis cada vez mais heterogêneos de públicos juvenis com lifestyle distintos.

Considera-se que, neste momento em que vivenciamos a experiência do pósfordismo, a publicidade ao comunicar produtos tangíveis ou serviços elege um viés cada vez mais subjetivo, simbólico, com conotações sociais. Neste cenário, os críticos da cultura do consumo reforçam os argumentos da desmaterialização do mundo e das vivências juvenis cada vez mais associadas às representações sígnicas da publicidade. (BAUDRILLARD, 2000; FETHERSTONE, 1991).

Assim o conceito de cidadania aparece cada vez mais presente nas associações simbólicas produzidas pelas corporações: para provocar um sentido de imersão na cultura das marcas que extrapola a relação com o processo tradicional de relação mercadológica, para sugerir a presença das corporações em todas as dimensões da vida social, política e cultural. E é neste sentido que vamos estudar o caso da campanha da marca Oi, Bloqueio não!

\section{A CAMPANHA OI, BLOQUEIO NÃO: PROMETENDO ENGAJAMENTO POLÍTICO E CIDADANIA PARA AS JUVENTUDES.}

Como vimos, os estudos culturais propõem a análise dos textos midiáticos partindo da análise contextual. Ao compreender as bases da economia política na produção do discurso é possível construir leituras críticas mais sustentadas. Por isso, vale uma breve referência à análise do mercado de Telecomunicações no Brasil e da posição da marca Oi, 
É possível se falar em política no consumo como recurso na promoção de marcas juvenis? Considerações a partir da campanha: oi, bloqueio não!

para em seguida compreendermos o conceito da campanha Bloqueio Não! e seus desdobramentos.

O mercado de Telecomunicações no mundo vem sofrendo mudanças substantivas desde a década de 90 em função em especial de duas variáveis: o processo da globalização e as velozes transformações tecnológicas. Compreende-se por Telecomunicações o processo de comunicação por meios elétricos, eletromagnéticos ou ópticos, em transmissão uni ou bidirecional. No Brasil até 1998, o controle estatal dos serviços de telecomunicações era hegemônico. A Lei Geral das Telecomunicações (Lei 9.472, de 16.07.97) inaugura o movimento de desestatização, estabelecendo mudanças substantivas no modelo e cria a ANATEL, agência reguladora para exercer as atribuições de outorgar, de regulamentar e fiscalizar o mercado de Telecom. E para atender especificamente o mercado de telefonia móvel foi criada a ACEL (Associação Nacional de Empresas Prestadoras de Telefonia Celular, em dezembro de 1998).

O modelo propõe, para telefonia móvel, a divisão do território nacional em áreas geográficas demarcadas. Atualmente o mercado tem oito grupos econômicos operando (Vivo, Claro, Tim, Oi/Telemar, CTBC/Algar, Sercomtel, Telemig/Amazônia/Opportunity e Brt/Brasil Telecom GSM) que consolidam as 40 prestadoras do Serviço Móvel Pessoal (SMP) atuantes nas quatro diferentes bandas de freqüência: A; B; C; D. A tabela, no anexo 01, demonstra a distribuição de operadoras, as tecnologias (CDMA/ TDMA/ GSM/ AMPS) e as regiões do Brasil onde cada operadora e suas prestadoras atuam. ${ }^{6}$

A Oi possui atualmente a autorização para prestar serviços de mobilidade para a Região I, que abrange estados do Norte, Nordeste e Sudeste, além da oferta de serviços de telefonia fixa, comunicação de dados, internet, longa distância em 16 estados do Brasil. A Oi atualmente é uma fusão da empresa Telemar Participações S/A (que prestava serviços de telefonia fixa, que, por sua vez, já fora um desdobramento da Telebrás após a desestatização em 1998) com a Oi telefonia móvel, criada em 2002.

A marca Oi em telefonia móvel entra no mercado com a intenção de construir posicionamento de imagem centrado nos conceitos de alta tecnologia (GSM); simplicidade (desburocratização de serviços) e jovialidade (buscando se conectar com as culturas juvenis). Em 2005, a marca lança a Oi Internet, com o portal de entretenimento e informações, assim como a Oi FM. É também nessa época em que a decisão da empresa é de trabalhar adotando uma marca única de convergência para todas as operações do Grupo

\footnotetext{
${ }^{6}$ Disponível em: www.acel.com.br Acesso em: 19 jun. 2008.
} 
É possível se falar em política no consumo como recurso na promoção de marcas juvenis? Considerações a partir da campanha: oi, bloqueio não!

Telemar. A marca Oi se apresentou como a mais adequada para se associar à noção de convergência. Posicionar a Oi como provedora integrada de soluções de informação, telecomunicação e entretenimento, geradora de economia de escala no marketing e reforçar a marca.

Neste contexto, a Oi Participações inaugura em maio de 2007 a campanha Oi Bloqueio não! com o objetivo de mobilizar as juventudes para tomada de posição frente à legislação de uso exclusivo de chips pelas operadoras. Endossando um projeto de lei que reivindicava a quebra do bloqueio de celulares, a Oi Participações encomenda para NBS uma campanha de vanguarda. O que se observa são dois movimentos simultâneos de construção de identidade com a causa: a campanha de um pseudo movimento social Bloqueio Não! de autoria, em tese, desconhecida. Movimento que aparenta ser da sociedade civil, mas que tem forte relação com a proposta da marca Oi. Em inúmeras mensagens da marca Oi aparece a aplicação da frase "a Oi apoia esse movimento". O que leva a crer que se trata de uma campanha que tem forte influência da própria operadora e depois mobiliza um número expressivo de participantes virtuais, no site Oi Bloqueio Não! ${ }^{7}$ A outra campanha é da Oi Participações, ratificando o discurso: A Oi apóia o movimento Bloqueio não! E que tem como proposição dominante enfatizar a liberdade de escolha do consumidor, buscando assim ganhar a simpatia do público juvenil para sua marca: aquela que se apresenta como defensora dos interesses dos jovens usuários de telefonia móvel. Prova disso é a edição especial da campanha na oportunidade dos eventos Fashion Rio e São Paulo Fashion Week, eventos patrocinados pela marca. A versão da campanha aqui foi explorar o slogan: “A moda nas ruas: aparelho desbloqueado no bolso". Para avaliar os conceitos da campanha vale adotar como fonte o texto cultural do filme para TV que se segue.

\subsection{Filme: Oi-desbloqueio-abandonados}

O filme é claramente uma continuidade à linha de comunicação da campanha da Oi: Bloqueio Não! na tentativa de mobilizar a sociedade brasileira para a adoção da causa do desbloqueio de chips da telefonia móvel ${ }^{8}$. No filme anterior personagens vestiam uniformes com o título "Operadora" e em coro cantavam: "Quem ama bloqueia!” em uma sátira à idéia de que se o bloqueio fosse bom as operadoras anunciariam dizendo: "Você comprou,

\footnotetext{
${ }^{7}$ O site, em última consulta, afirma que 1. 533.298 usuários aderiram ao movimento Bloqueio Não!.Disponível em: www.bloqueionao.com.br. Acesso em: 04 jul. 2008.

${ }^{8}$ www.oi.com.br/bloqueionao ANATEL e regulamento para o bloqueio de celulares.
} 
É possível se falar em política no consumo como recurso na promoção de marcas juvenis? Considerações a partir da campanha: oi, bloqueio não!

de Mônica Machado

mas o celular é nosso!”. Os personagens uniformizados retornam no novo filme, mas agora tem algemas e estão em busca de parceiros. A $1^{\circ}$ cena é de um rapaz uniformizado tentando convencer uma moça a aderir à causa do bloqueio. A moça por sua vez foge do rapaz e vai embora. Na sequência, diversos uniformizados tentam algemar várias pessoas e não conseguem e até um cachorro foge deles. A locução acompanha dizendo: "Graças às denúncias da Oi, o Brasil abriu os olhos para o bloqueio de celular. E agora milhares de pessoas estão livres do bloqueio de seus aparelhos". A voz do locutor se torna mais enfática com a imagem de um casal em uma sala escura, algemados. Um martelo bate nas algemas ao mesmo tempo em que o locutor profere a frase: "Você também pode ser livre". $\mathrm{O}$ rapaz comemora como se estivesse em um campeonato de futebol. Ao fundo, ouve-se o som de uma torcida. Entra em foco um rapaz com a loja da Oi como cenário no fundo e diz: "Desbloqueie o seu celular e use o chip que você quiser. Em respeito a você a Oi apoia o desbloqueio e só vende aparelhos não bloqueados". Enquanto o rapaz fala, aparece o texto em uma tarja preta na parte superior do vídeo: Se você tem um Oi, desbloqueie grátis em qualquer loja Oi. E na parte inferior: www.oi.com.br/bloqueionao. Novamente o locutor em off diz: "Liberdade assim só na Oi". Voltam à cena os uniformizados "Operadora", todos chorando em torno de uma fogueira como moradores de rua e cantam: "Quem ama bloqueia...". A cena conota o fracasso do movimento de defesa do bloqueio. Entra em cena uma menina pequena aparentando no máximo cinco anos em um cenário azul e diz: Oi! Acompanha a logomarca da operadora e sua assinatura: Simples assim. Na tarja preta que fecha a cena final vem o texto: Para mais informações consulte: www.oi.com.br/bloqueionao.

\subsection{Analisando os discursos de liberdade e direitos à cidadania na campanha da Oi.}

A campanha então produz um manifesto em defesa da liberdade de escolha: convida seus consumidores para a participação na cena política clássica, propondo o recolhimento de assinaturas para mudança da lei de bloqueio de chips de telefonia móvel. O filme traduz a tendência contemporânea de revelar estratégias de branding de imersão na vida social, política e cultural de seus consumidores (BAUDRILLARD, 1995; SLATER, 2001; KLEIN, 2004).

Chama atenção, no discurso publicitário da marca Oi, a constância da referência à idéia de liberdade traduzida por certas noções: a metáfora da algema; as expressões "liberdade de escolha" ou a promessa do locutor do filme: "Você também pode ser livre". E 
É possível se falar em política no consumo como recurso na promoção de marcas juvenis? Considerações a partir da campanha: oi, bloqueio não!

ainda o apoteótico fechamento em slogan de marca: "Liberdade assim só na Oi”. O que se observa então é que as garantias do sujeito para agir como politicamente correto lhe são oferecidas na ativação de seu papel de consumidor-cidadão. Na direção do que sugere Foucault (2002) a proposta busca a adesão não simplesmente ao produto, mas aos valores das corporações, que são articulados com os valores dos grupos que constituem seu públicoalvo. Nessa perspectiva, o liberalismo exerce o poder de modo capilar, inscrito nas formas de produção das instituições. As estratégias de subjetividade são associadas ao autocontrole: o eu que tem poder de escolher e se autogoverna.

A estratégia de poder aqui autoriza o sujeito a ser agente ativo no processo de escolha, contanto que não deseje sair da cena do consumismo. O slogan que diz: "Liberdade assim só na Oi" é revelador desta tendência: o aprisionamento simbólico do poder de liberdade às marcas. O que não se pode desejar é a liberdade fora da lógica do sistema. Caso você fique na Oi, o acesso à liberdade está garantido. Você está com a marca porque foi seduzido por ela, não por uma convenção arbitrária. Seu processo de escolha é que lhe fornece a liberdade. Trata-se, portanto, de uma premissa do ideal do liberalismo.

Não esteve no foco deste projeto estudar a recepção, mas é revelador observar que o movimento de defesa da causa do desbloqueio tenha mobilizado mais de um milhão de jovens para certa "militância virtual". Tal fenômeno muito provavelmente não ocorreria se o objeto do debate fosse uma ação referida à representação política clássica. Nota-se a tendência contemporânea das juventudes de buscar a adesão a causas cada vez mais vinculadas ao universo das marcas.

\section{CONSIDERAÇÕES FINAIS}

Ao analisar a campanha da Oi, compreendemos que esse modo de inscrição do poder na modernidade tardia que autoriza o sujeito a agir politicamente pela mediação do consumo reforça a hegemonia da ideologia liberal. Entendemos que esses agenciamentos modernos de construção da cidadania planetária mediados pelo consumo promovem a idealização do poder juvenil nas transformações sociais e políticas. Em certo sentido, com a profusão de mensagens publicitárias dizendo para os jovens que eles estão autorizados a exercer poder em sua condição de "consumidores-cidadãos", acaba por se revelar como dado de realidade. Com destaque específico para essa campanha do Oi Bloqueio não! entendemos que esses discursos conduzem à idéia de que, partilhando de um movimento em defesa da causa do desbloqueio de aparelhos celulares, o sujeito é ativo em seu papel de 
É possível se falar em política no consumo como recurso na promoção de marcas juvenis? Considerações a partir da campanha: oi, bloqueio não!

cidadania. O problema está na reflexão do quanto tais inserções de fato são fortalecedores da participação política ou apenas inserem o jovem em um cenário fragmentado de engajamento que se encerra no interior da lógica do consumo. Por isso torna-se fundamental nos dias de hoje o investimento em uma formação pedagógica crítica mais incisiva para que as juventudes possam avaliar os discursos corporativos mediados pela publicidade, podendo escolher seus vínculos de identidade com os bens tangíveis e simbólicos com mais isenção e distanciamento.

Neste sentido, compartilhamos do sentimento de preocupação de Klein (2004) com o movimento do "branding da aprendizagem". . Se as marcas passam a povoar o ambiente acadêmico e são co-participantes da formação intelectual dos jovens, a ampliação do debate das conseqüências destas novas paisagens culturais deve ser prioridade nos fóruns deliberativos nos centros de ensino. Assim como entendemos que se torna urgente repensar modos de sensibilização das juventudes para o processo político convencional para que passe por argumentos que contribuam no fortalecimento dos espaços institucionais de participação democrática. Espaços esses que atualmente se mantêm em progressivo distanciamento das culturas juvenis. Se o consumo é o atual campo simbólico de mobilização dos códigos culturais juvenis, há pistas revelando que, ao invés de se considerar consumo e a política como campos antagônicos, seria mais produtivo encontrar saídas para dialogar com as juventudes através das práticas de consumo, propondo questionamentos sobre as suas inclusões nos sistemas de representação democrática; ações de participação coletiva estimulando as deliberações comunitárias e não ao culto ao individualismo e, ainda, agendas que apresentem saídas para que a participação juvenil seja de fato reconhecida como fundamental para criação de novas políticas públicas sustentáveis no mercado de marcas publicitárias.

\section{REFERÊNCIAS BIBLIOGRÁFICAS}

AKATU divulga pesquisas sobre jovens." In AKATU. Disponível em: $<$ http://www.akatu.net/>. Acesso em 26/07/2007. BLECHER, Nelson. "Consumo Jovem: como abordar um público afluente, mas avesso às mensagens comerciais" in

\footnotetext{
${ }^{9} \mathrm{~A}$ jornalista canadense discute a cultura de patrocínio que invadiu as instituições de ensino fundamental e universitárias do Canadá e EUA. Propõe refletir sobre o quanto a presença das corporações nos ambientes educacionais fere a autonomia pedagógica para reflexão crítica sobre a sociedade de consumo. E ainda, se o mundo das marcas corporativas se confunde com a aprendizagem formal, as ideologias das culturas juvenis tendem a passar, obrigatoriamente, pelas mediações do consumo.
} 
É possível se falar em política no consumo como recurso na promoção de marcas juvenis? Considerações a partir da campanha: oi, bloqueio não!

Exame, 08/12/2003. Disponível em:

<http://pubweb.abril.com.br/exame/v/index.jsp?vgnextoid=36beaf8791864010VgnVC

M1000000b0417acRCRD\&vgnextrefresh=1\&vgnextnoice=1>. Acesso em: 26/072007.

BURKE, Eliza. "Feminine visions: anorexia and contagion in pop discourse." in Feminist Media Studies, vol. 6, $\mathrm{n}^{\circ}$ 3, p. 315-330, 2006. CANCLINI, Nestor García. Consumidores e Cidadãos. 4. ed. Rio de Janeiro: UFRJ, 1999. DOUGLAS, Mary \& Isherwood, Baron. O Mundo dos Bens: para uma antropologia do consumo. Rio de Janeiro: UFRJ, 2004.

"Eles Gastam Muito." in Veja Jovens: edição especial, 07/2003. Disponível em: <http://veja.abril.com.br/especiais/jovens_2003/p_080.html>. Acesso em: 26/07/2007.

FISKE, John. Commodities and Culture. In: Understanding Popular Culture. London: Unwin Hyman, 1989.

FOUCAULT, Michel. A “Governamentalidade”. In: MOTTA, Manuel Barros (org.), Estratégia, poder-saber. Ditos e escritos: vol. 4, p. 281-305. Rio de Janeiro: Forense Universitária, 2006 [1978].

FREIRE FILHO, João. Formas e normas da adolescência e da juventude na mídia. In: FREIRE FILHO, João e VAZ, Paulo (orgs.). Construções do tempo e do outro: representações e discursos midiáticos sobre a alteridade, p. 37-64. Rio de Janeiro: Mauad X, 2006.

GRIFFIN, Christine. "Troubled teens: managing disorders of transition and consumption." in Feminist Rewiew, n 55, p. 4-21, 1997. . Representations of Youth: The Study of Youth and Adolescence in Britain and America. Cambridge: Polity Press, 1993.

HALL, Stuart. Da Diáspora. Identidades e Mediações Culturais. (org. Liv SOVIK). Belo Horizonte: UFMG/Brasília: UNESCO, 2003.

KELLER, Margit. "Freedom calling: telephony, mobility and consumption in postsocialist Estonia." in European Journal of Cultural Studies, vol 8, n. 2, p. 217-238, 2005.

KLEIN, Naomi. Sem logo. São Paulo: Editora Record, 2004.

MILES, Steven et al. The changing consumer: markets and meaning. London: Routedges, 2002.

OSGERBY, Bill. Youth media. London: Routledge, 2004. 
É possível se falar em política no consumo como recurso na promoção de marcas juvenis? Considerações a partir da campanha: oi, bloqueio não!

ROCHA, Everardo. Magia e capitalismo: um estudo antropológico da publicidade. 3. ed. São Paulo: Brasiliense, 1995.

SIMMEL, Georg. As Grandes Cidades e a Vida do Espírito. WAIZBORT, Leopoldo (Trad.). "Die Grobstädte und das Geistesleben" (1903). in Georg Simmel Gesamtausgabe, Frankfurt/M, Suhrkamp, 1989 ss., vol. 7, p. 116-131.

SLATER, Don. Cultura do Consumo e Modernidade. São Paulo: Nobel, 2002. \& MILLER, Daniel. Moments and Movements in the Study of Consummer Culture: a discussion between Daniel Miller and Don Slater in Journal of Consumer Culture, n. 7; 5, p. 5-23, 2007.

TIERSTEN, Lisa. Marianne in the market: envisioning consumer society in fin-desiècle France. Berkeley: University of California Press, 2001.

UNEP \& UNESCO. "Is the Future Yours? A research project on Youth and Sustainable Consumption." In UNEP. Disponível em: <http://www.uneptie.org/pc/youth_survey/index.htm>. Acesso em: 26/07/2007. . "Youth, Sustainable Consumption Patterns and Life Styles. Managemente of Social Transformations", 2001. in UNESCO. Disponível em: $<$ http://unesdoc.unesco.org/images/0012/001242/124238e.pdf>. Acesso em: 26/07/2007.

Artigo recebido em 13/7/2009.

Aprovado em 23/8/2009. 